\title{
Citation and Referencing Support at an Academic Library: Exploring Student and Faculty Perspectives on Authority and Effectiveness
}

\author{
Lydia Dawe, Jackie Stevens, Bob Hoffman, and Morgann Quilty
}

\begin{abstract}
Libraries expend considerable time and effort in providing instructional resources to help students learn the "mechanics" of citation and referencing. However, there are few studies that examine the efficacy of these resources. Using focus group methodology, the authors explored student and faculty perspectives about citation practices through their use of the library's online referencing guide. It was found that faculty struggled to instill "real world" meaning for students around academic integrity practices, while students reported feeling confused and somewhat intimidated about the scholarly writing process. Findings reveal the importance of situating referencing within a positive, holistic approach to academic integrity that emphasizes critical thinking and student autonomy.
\end{abstract}

\section{Introduction}

At the University of Notre Dame Australia (NDA), instilling the values of academic integrity in students is a shared priority among academic faculty, library professionals, and other instructional support services. ${ }^{1}$ NDA adopts the definition of academic integrity from the International Center for Academic Integrity: "adherence to the values of honesty, trust, fairness, respect, and responsibility" by all of those involved in scholarship. ${ }^{2}$ Citing sources, or "referencing," ${ }^{3}$ is generally accepted to be a vital part of this concept. The Association of College and Research Libraries' (ACRL) Framework for Information Literacy for Higher Education describes the citation process as both a method of acknowledging and respecting the ideas of others ("Information Has Value") and as a way of showing diverse or competing perspectives on a topic ("Scholarship as Conversation"). ${ }^{4}$ However, the literature shows that faculty struggle to convey the importance of referencing as both an ethical concern and a practical skill to students. ${ }^{5}$ Students frequently focus their attention on the "mechanics" of citation (the formatting of references) in an effort to avoid adverse outcomes. ${ }^{6}$ Meanwhile, libraries strive to meet students at the point of need.

\footnotetext{
*Lydia Dawe is a Liaison Librarian, Health Sciences and Jackie Stevens is Manager, Research Services at the University of Notre Dame Australia; email: lydia.dawe@nd.edu.au, jackie.stevens@nd.edu.au. Bob Hoffman was Liaison Librarian, Education at the time of this study and is currently an Academic Sessional at the University of Notre Dame Australia; email: bob.hoffman@nd.edu.au. Morgann Quilty was Manager, Library Services at The University of Notre Dame Australia at the time of this study and is currently Associate Dean for the Learning Commons of Parkland College (Urbana-Champaign, IL); email: mquilty@parkland.edu. (02021 Lydia Dawe, Jackie Stevens, Bob Hoffman, and Morgann Quilty, Attribution-NonCommercial (https://creativecommons.org/licenses/by-nc/4.0/) CC BY-NC.
} 
A cursory Google search shows that many academic libraries in Australia, North America, and the UK offer a range of referencing and citation instruction, guides, and Q\&A services. At NDA, referencing instruction is mostly provided by faculty within courses, with the library offering workshops in the first weeks of the semester. Beyond these sessions, students can access referencing support through the library's chat and video call services, guides, FAQs, and help desks. As evidence showed that student use of referencing support services had been increasing, we felt that it was important to explore how they were used, whether they were effective, and in what ways they might be improved.

\section{Background}

Responsibility for the provision of citation assistance and advice tended to fall to the NDA library by default rather than by directive. An inconsistent approach to citation guidance existed at the University, with some faculty taking responsibility for creating citation guides and providing associated instruction, and others leaving these duties to the library. This placed the library in a reactive position when offering support, as it became apparent that "local" variations between faculty or discipline-based citation guides resulted in confusion for students and for the library staff members assisting them. Examples and rule interpretations varied widely, and were sometimes contradictory. This made it problematic for library staff to provide authoritative advice when it appeared to be at odds with individual instructors' positions.

In an effort to improve the student experience with referencing, the library and the University's Academic Council-our primary academic committee-discussed ways to address these inconsistencies. It was concluded that the library was best positioned to act as the "authority" for the application of citation styles. The number of citation styles endorsed for use at the University was then reduced from fourteen to three, consisting of an author-date style (American Psychological Association Publication Manual - "APA"), a footnoting style (Chicago Manual of Style - Notes \& Bibliography - "Chicago"), and a legal citation style (the Australian Guide to Legal Citation - "AGLC"). The Academic Council agreed that teaching faculty should refer questions or minor disagreements about how to apply the styles to the University library for resolution. The library was also to create an examples-based online referencing guide (henceforth referred to as the "Guide") to provide supplemental instruction.

The new Guide was published on the library website the following semester. After reviewing twelve months of usage statistics and user anecdotes, library staff generally felt confident that the Guide improved students' experience. Focus groups were used to further explore the user perspective of the citation process and determine the efficacy of the guide. We also wanted to ascertain whether the library's role as the authority in this area was clear to staff and students. The research questions for this project were:

- What are the student and faculty opinions of the Guide?

- What are the student experiences of the citation process?

- What is the faculty perspective on student citation skills?

- Who do students and faculty think should be teaching citation skills?

\section{Literature Review}

Faculty play a key role in teaching, assessing, promoting, and supporting academic integrity, but approaches and attitudes to developing student ability in this area tend to be uneven across and within institutions. ${ }^{7}$ Mixed messages about roles and responsibilities can start at a policy 
level. In their review of Australian university academic integrity documents, Bretag et al. observe that statements on accountability and punishment are largely aimed at students, with only 36 percent naming the roles of other key stakeholders (such as faculty or the university itself). ${ }^{8}$ Academics surveyed by Löfström et al. agreed that academic integrity is an essential part of the research process and that academics have the knowledge and competence to teach it. ${ }^{9}$ However, there was disagreement about methods (for example, should it be taught in a classroom or modeled in practice?) and principles (such as whether academic integrity is a skill or a value). Peters, Boies, and Moran's investigations describe a "haphazard" approach to teaching in which faculty assumed both active and detached roles depending on the skills being taught. ${ }^{10}$ Michalak et al. found that faculty disagree on the very definition of plagiarism and how much emphasis it should be given in the classroom. ${ }^{11}$ Vardi goes further, contending that, as students do not necessarily intend to deceive when making referencing errors, it is a mistake for faculty to equate those errors with cheating and plagiarism. ${ }^{12}$

Student understanding of and adherence to principles of academic integrity, including citation practices, is of increasing concern. ${ }^{13}$ Greenwood et al. found that 97 percent of students considered citing sources to be important or very important in their work. ${ }^{14}$ The large survey on academic integrity in Australian universities conducted by Bretag et al. showed that 89 percent of students agreed they received enough "information" on the topic, while 68.2 percent agreed they received enough "support and training." ${ }^{15}$ When students are supposed to get this "support and training" is disputed. Peters and Cadieux found that 82 percent of faculty surveyed expected undergraduate students to have sufficient referencing skills prior to commencing their studies, whereas 94 percent of students expected referencing skills to develop during their studies. ${ }^{16}$ Driven by fear of failure, students often devote most of their attention to the mechanics of citation, losing confidence in their academic literacy skills. ${ }^{17}$ Interviews with faculty show that by being "hung up" on style, students tend to overlook the relationship between citation and credibility in academic writing. ${ }^{18}$ However, faculty themselves are not immune from defaulting to a mechanical approach. Content analysis by Head and Eisenberg of 191 assignment handouts showed that most instructors favored a "checklist" approach that emphasized outcome (standards and grades) instead of process (researching and referencing). ${ }^{19}$ These results show an inclination to present research as linear rather than iterative, as if students will succeed if they just follow the right steps.

Although the ACRL's Standards for Libraries in Higher Education includes academic integrity support as a key professional value, external perceptions of the librarian's role in its instruction vary. ${ }^{20}$ While some faculty view collaboration with librarians as important to academic integrity instruction, ${ }^{21}$ Ard and Ard's faculty survey on library roles revealed that "educating students about plagiarism" and "teaching citation styles" were ranked low among the library's perceived responsibilities. $^{22}$

The ubiquitous availability of online materials and many new types of materials has made citing sources more challenging. ${ }^{23}$ In his 2014 study, Kargbo found that 62.1 percent of undergraduates were not confident in their ability to cite sources correctly and that even those who considered themselves confident often produced inconsistent references. ${ }^{24}$ This growing complexity of source types may be one of the reasons libraries are fielding an increase in student citation questions. ${ }^{25}$ Another may be the unique position libraries have in students' academic life. Libraries also tend to be more accessible to students than other support services, as they are open long hours and are available at the moment of need.$^{26}$ Buranen describes 
libraries as a "safe place" for students to check their citation practices, as library staff focus on supporting learning rather than investigating misconduct. ${ }^{27}$ Although positioned at the center of the academic experience, librarians are outside the power structure of assessment and grading; they are often part of an interdisciplinary academic skills team. ${ }^{28}$ This combination of factors may contribute to libraries becoming a de facto rather than a designated position as the authority for citation expertise.

The literature shows that libraries are expending a lot of time and attention in providing specialized citation advice, including online tutorials, guides, FAQs, instruction, and specialized one-on-one support services. ${ }^{29}$ To measure a service's success, libraries have traditionally relied on quantitative data (door counts, circulation statistics, downloads, page views, reference desk queries); however, such data is limited in what it can reveal. ${ }^{30}$ As Priestner and Borg state:

...the efforts undertaken are immense and the services [libraries] deliver are fiendishly complicated to manage and sustain. Unfortunately, however, far fewer efforts are directed towards evaluating the success and efficacy of the services we provide: how well they meet user needs; whether user experience of them is good, bad, or average. ${ }^{31}$

Despite the ubiquity of these services, we encountered a dearth of literature regarding the evaluation of library citation guides or support materials. This study will help to fill this gap in the research and provide a foundation for further studies on citation support.

\section{Method}

Following approval of the study design by the School of Education's Research Committee, four librarians launched the investigation. In April 2016, 33 undergraduates, two postgraduates, and 14 faculty members participated in focus groups held at Notre Dame's Fremantle and Sydney campuses. In the interests of gathering the largest possible number of participants, the research team did not limit recruitment to specific disciplines, academic levels, or genders. Undergraduates were recruited through class visits by library staff and via flyers posted around the campuses; postgraduate students were contacted via email through the university's Research Office. Faculty were contacted via email through the relevant staff email lists. Tea, coffee, and pastries were offered to incentivize participation.

Focus group participation was defined by population (undergraduate, postgraduate, or faculty) and by the citation style typically used in their discipline area (APA, Chicago, or AGLC). Groups were generally made up of three to six participants, and sessions were led by a facilitator. A note-taker was also in attendance to write down impressions of the group's dynamics, record conversation topics, and note body language. The session notes were later used to verify the main points in each discussion and illustrate the nature of consensus on a topic, as well as to highlight any other nonverbal elements that indicated the importance or relevance of a point. Discussions were audiorecorded using an iPad and the Voice Record Pro app, ${ }^{32}$ and a laptop displaying the Guide was available to consult. A set of semistructured questions were preprepared for facilitators (see appendix), though free association was encouraged to allow the group to explore topics related to citation, even if they deviated from the original questions.

Following the focus group sessions, the audio recordings were transcribed by the research team; participant responses were de-identified. The research team used NVivo 11 software $^{33}$ 
to collate and analyze the transcripts. We used the steps outlined in Braun and Clarke's guide to thematic analysis to code the results. ${ }^{34}$

\section{Results}

In focus group studies, the unanticipated nature of participants' responses is one of the rich outcomes of the data collection. As a result, answers to the discussion questions are consolidated into broader themes.

Faculty participants conveyed the complexities of teaching critical scholarly writing skills. When and how to introduce citation mechanics was an important issue: "it is a balancing act." One faculty member felt that, if introduced too early, the "real world" implications could be overlooked. Another agreed: "the biggest challenge is to get the students to realize that this is something that needs to stay with them throughout their whole degree... and beyond, in professional practice." On the other hand, if introduced too late, the skills could not be applied properly in coursework. A few participants were concerned that messages about referencing were not reinforced properly in subsequent courses and that "a little booster" instruction would be helpful.

Citation instruction appeared to be inconsistent across undergraduate courses at our institution. Some students received several weeks of instruction, whereas others would have one assessment or in-class activity that focused on citation. Some students relied on optional workshops provided by the library. Others mentioned that academic staff did not always set a good example regarding formatting references in course materials. One student described a situation where she had copied a citation directly from the course outline and was then told her formatting was incorrect. Another student was frustrated by the inconsistent ways referencing was explained to her by various tutors. When these comments were put to academic staff in a focus group session, staff members responded, "Our own modelling...it's more than inappropriate," and "if we can't do the right thing, why should they?" Some academics admitted that not all instructors had the same level of competency with the university's chosen citation styles; as a result, they were inconsistent in their assessment standards.

Students also found that some instructors were very insistent about APA document formatting, whereas others had no set preference: "I'm doing [course name], she wants it like this, I'm doing [other course name], she wants it like this." Academic staff acknowledged the difficulty of implementing a set format for documents across the faculties: "You wouldn't get uniform acceptance. I think you'd be opening a can of worms."

In spite of comments around inconsistencies in citation instruction, student responses reflected a strong degree of trust in both library staff and their lecturers and tutors when asking for help. Both faculty and librarians were considered to have authority and expertise, though, in general, students saw librarians as having more specialized knowledge on citation than faculty: "If I was going to ask anyone I would probably ask one of the librarians," "It probably should be [librarian's name] because all the professors when they don't know something they go to [her]...I just get that impression," and "I would [go] to the lecturers, but also more to the library, because I do have [librarian]'s email I would probably ask him." This type of answer was particularly prevalent in students who had experienced librarians teaching their courses. However, one student had doubts about going to the library desk: "I have gone to the library to ask questions, but the librarian I asked wasn't familiar with [Chicago style]." Despite this, most students felt that faculty had the ultimate authority on citation styles given 
that they are responsible for grading the work. One group felt differently, pointing to the official standard itself: "If everyone is looking toward the reference guide then the reference guide needs to be the authority."

Faculty varied in their views on the process of teaching and assessing citations, although it was generally agreed that it was important to be well-informed: "if you're setting the assessment rubrics... allocating the grades...that's an academic responsibility." However, it was also acknowledged that there was often not enough space in a curriculum to devote to the topic: "I wouldn't have time to give up a tutorial just for referencing." Most faculty felt that the "final say" on citation issues should lie with them as discipline experts, in consultation with the official manuals. However, librarians were frequently referred to by faculty as consultants in the process: "the library's contribution has been invaluable to my unit," or as support personnel: "I can direct [students] to [the library] if they're having trouble or needing some feedback." A few faculty were happy to defer completely to librarians: "that seems to be your area of expertise."

The focus groups proved insightful in providing the student perspective on the process of citing sources. A few undergraduate participants had learned about referencing during high school or in previous study, but most were learning for the first time in their current degree programs. First-year students found the information-overload at the start of semester particularly overwhelming: "I think that was something that, especially for the first week, was pretty intense." Some students reflected on the negative way that referencing was introduced to them:

You always get the same talk: [if] you don't reference, you're plagiarizing. If you're plagiarizing, we find you, you'll have to repeat the unit. It's always the same. They're doing it for a reason because they're trying to emphasize [that] if you don't do it properly, you're not going to pass Uni. But as a first-year student, you're sitting there going, "I' $m$ the only person in this class. I' $m$ going to die."

Most of the students interviewed said that they would "reference as [they] go," usually by jotting down notes about sources at key points in the document. A few students said they would wait until the end of assignments to add references. Some students complained that they were not provided with a clear process for incorporating references into their workflow: "I learned to after...but [course instructors] didn't tell you ways to reference. So my first assignment I'm like drowning in paper and I've highlighted things and I'm like 'AARGH!"' Others were more successful in their workflows as they had experience from previous degrees, had participated in library classes, or had taken an academic preparation course or workshop.

Many students (and some faculty) declared a preference for having a printed copy of the Quick Guide (an abridged, printable version of the full guide provided by the library) on hand as they worked. As a result, some suggested that the entire NDA guide be available in a print-friendly format: "I think that should be there for people who do like having a hard copy," or "something I can print out and just have on hand."

While student comments revealed that their attitudes and practices around citing sources was varied, faculty responses demonstrated the underlying complexity of their role in instructing and assessing students' understanding and skills. All participants in the faculty focus groups were involved in teaching or grading citations in either undergraduate or postgraduate 
work, though there was a mix of assessment approaches. For some, grading referencing was specific (generally in first-year undergraduate courses), and others assessed student practice in general. We first asked faculty to describe their experiences in assessing student work. One participant found that, while some students did well in the technical aspects of citations, they faltered when it came to incorporating research into their work: "[students make] broad statements without supporting it with citation literature." Another participant agreed, adding: "they see [referencing] as a formality, a hoop to jump through...[instead of] 'No, this is about you critically evaluating the research that you read and knowing what it's actually saying."' One faculty member, who worked in an academic advisory role, had also witnessed students' mechanical approach: "I don't think they have an understanding of their voice and then [using] evidence to support their voice. I think they see referencing as just getting the bit in italics that needs to be in italics. I think when we talk referencing, those students see mechanics." She also described students coming to her with completed essay drafts that contained no references, with the student assuring her that the sources would be "added in after."

One of the original study questions was to assess users' experience with the guide. Overall feedback from all participants was positive, which affirmed that the approach the library had taken was seen to be broadly valued by the community. Both faculty and students appreciated the number and variety of examples that the online format allowed. Some faculty mentioned that students often struggled with how to classify certain sources and required guidance in locating examples: "they're not always sure whether it comes under web source or a couple of different slots." Several students confirmed that common sources (such as books and journals) were easily found, but web sources proved more challenging: "like a website that refuses to be a website and it's actually a journal article or something like that." Several participants mentioned how much they appreciated the multicolored sample citation placed at the top of each page, which illustrated the components of a reference (see figure 1). This tallies with Van Note Chism and Weerakoon's findings that students find color coding more "user friendly" and "efficient" to use than plain print. ${ }^{35}$

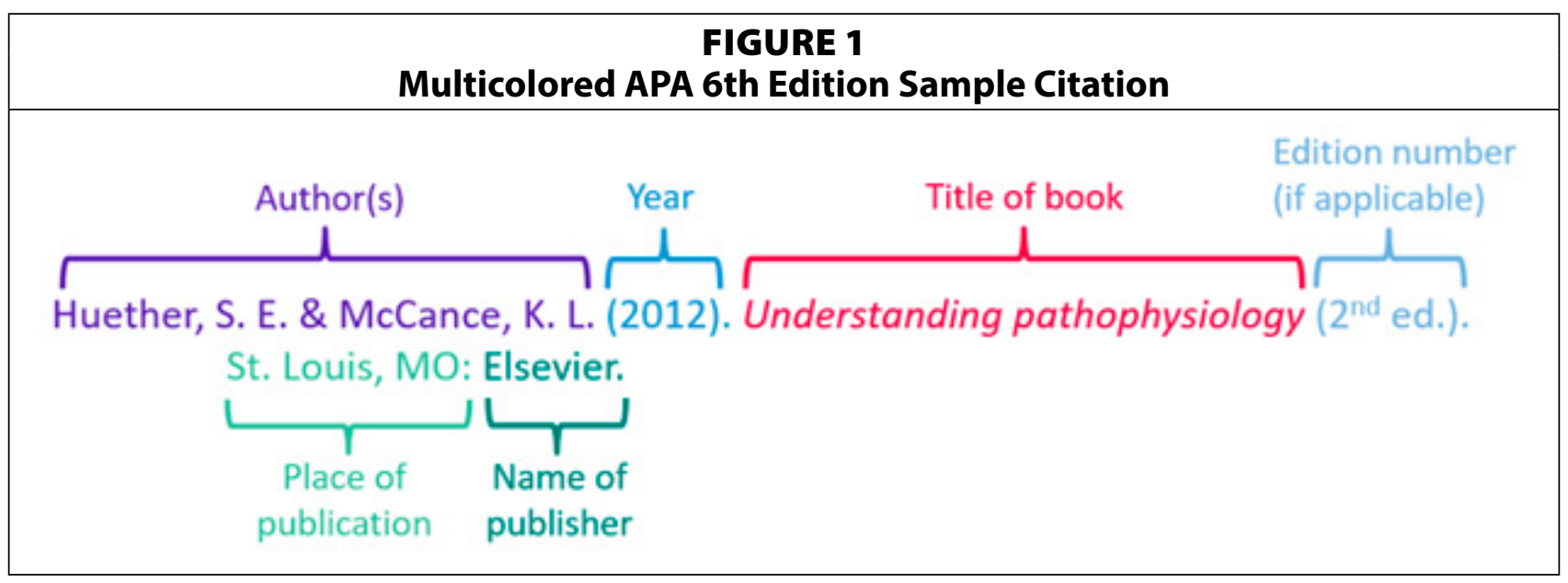

Each group was asked if they used the guides' search function to find information. Several participants mentioned that search boxes can be problematic "if you don't know what you're looking for." Other participants suggested that the search box contain suggestions that appeared as the user typed, similar to Google. 
Finding information on secondary source citations appeared to be of pressing concern to students. APA's Publication Manual does not encourage the practice of using secondary source citations, so the library had made this information less prominent in the guide. Several academics were quite firmly against providing instructions: "I tell them to find the original source and if they absolutely can't, not to [use it as a] reference." However, others acknowledged the "shades of grey" in the situation, especially when important sources are locked behind subscription paywalls or unavailable locally in print. Students struggled to identify a likely location in the guide for this information and often did not have a word or phrase to describe this kind of citation, making it difficult to search for.

In creating the guide, the library aimed to match the language of the style manuals for consistency's sake. However, a few issues with the language were mentioned, including the words "parentheses" ("we all mean brackets"), "secondary source citations" ("I wouldn't know that phrase"), and "multimedia" ("not that hard a word, but-I don't know if I would necessarily think of $i^{\prime \prime}$ ). As some of the terms are not self-explanatory, participants suggested that more explanation be provided in the guide.

Faculty members reinforced the importance of the university providing a well-vetted inhouse citation guide for students to use rather than having them browse manuals or the internet: "[students] don't know how to interrogate the quality of that information to know if it's current and accurate." Although most students used NDA's citation guide, they also used guides from other universities. The library's two citation management tools, EndNote and RefWorks, were mentioned by students as helpful but fallible: "you've got to check them...minor mistakes can come through." Faculty tended to caution students against using these tools before they had a solid understanding of a citation style: "I've corrected [students'] references and they say 'but I used EndNote!' [...] obviously it's not doing it correctly. You still need to know [how to reference]."

Another key source of citation assistance was the library's "AskUs" service (LibAnswers by Springshare), in which users could either submit a question to library staff for a response or search the knowledge bank of answers to existing questions. However, it appeared that this service was not visible enough to students, as several students called for a "question and answer" service for citation questions in particular. One student even proposed the model of the AskUs service without knowing that it already existed:

[The library should have] an "ask question" thing on the website... You put it up there and then the library could go "look, this is how you do it." Like you know how you go to Yahoo Questions or whatever? You type in the question and it already comes up, someone has already answered it.

The library also offered video tutorials on the mechanics of citation on the website. Several students were aware of these, but there were mixed responses regarding their usefulness. Interestingly, some students considered the video format cumbersome in terms of access ("sometimes I'm in the middle of class or in the library and I don't have my headphones") and time ("I like videos but I don't think I would watch the whole thing") even though the videos were generally only 3 minutes long.

\section{Discussion}

The main limitation of this study was the small sample size and lack of participant diversity. 
The students were mostly undergraduates, there were very few faculty represented, and the majority were from the Fremantle campus. However, the focus group dynamics were positive and responsive for the most part, and the format allowed participants to bring forth issues that were clearly important to their experiences in learning and teaching citation methods at the university.

The aim of this project was to gather faculty and student opinions of the library's citation guide, as well as to gain insight into the teaching and learning process. The library team also sought to determine who participants felt was the "authority" in providing citation support and instruction. We feel that our project achieved these aims, and the more meaningful findings are outlined in the themes below. However, we gained less information than expected regarding the guide's layout, content, and structure, as well as the overall student user experience. We found instead that participants preferred to discuss the bigger-picture issues surrounding citations and scholarly writing skills - the way it is contextualized, taught, and assessed. We decided that, in future, live user testing on a revised prototype guide, as recommended by usability experts Steve Krug and Andy Priestner, ${ }^{36}$ would yield more specific results in this area.

Many academics agree that students need to understand more than just the rules surrounding academic integrity; ethics, standards, and values are key parts of the conversation. ${ }^{37}$ However, as research tends to focus on the lack or absence of academic integrity, there is a tendency for faculty to frame the conversation in a negative way. ${ }^{38}$ It appears that the ways citation skills were contextualized, taught, and graded at NDA created a stressful situation for the students we questioned. Positioning citation skills alongside punitive outcomes (such as accusations of plagiarism) created unfavorable associations with academic literacy from the start. Ominous lectures about the consequences of plagiarism were particularly troubling to first-year students. Gravett and Kinchin conclude that anxiety from "scare speeches" results in students losing a sense of self-motivation and agency. ${ }^{39}$ Sefcik et al. suggest trying a more holistic approach to academic integrity that encourages students to develop their own values, principles, and beliefs, creating a sense of autonomy and avoiding a "culture of fear." 40

First-year undergraduates are often unfamiliar with the types of sources they are expected to use at university. ${ }^{41}$ Most of our student participants were new to referencing and had no sense of what process to follow. Seemingly as a result, students become preoccupied with citation mechanics. To faculty participants, it appears that students view referencing as an unpleasant formality, separate from the spheres of evaluation or argument. There are a number of ways to possibly address this issue. Vardi suggests removing citation skills from the context of plagiarism, spending less time on mechanics, and emphasizing the relationships among referencing, critical thinking, and analysis. ${ }^{42}$ Margolin and Hayden's undergraduate "Research Toolkit" website presents the research process in a nonlinear fashion and guides students toward more conceptual models of inquiry. ${ }^{43}$ The role for the NDA Library in citation and referencing instruction remains ambiguous. In the literature review Positioning the Academic Library within the Institution, John Cox reflects that academic libraries are increasingly expected to "give up territory, recognize interdependencies and embrace ambiguity." 44 This phrase reflects the challenges that NDA Library faces with citation instruction. Both student and faculty participants reported inconsistencies across university courses. Possible reasons for this may include curriculum space, assumptions about prior instruction, and differing opinions on the importance of the topic. As this issue arose unprompted in all the student focus groups, it may be indicative of a widespread problem. Students appeared bewildered 
and stressed by the differences they observed as they moved between classes. When citation instruction was present, it tended to be added to the already packed first-year curriculum, with emphasis tapering off in subsequent years. While the library has streamlined matters by standardizing the "how" (mechanics) of referencing, it appears that messages about the "why" (academic values and "real world" applications) can become complicated by the circumstances of the messengers. ${ }^{45}$

Our findings also suggest that students still struggle to categorize document types. Student participants became frustrated when citing less conventional information sources, or, as one student put it, "a website that refuses to be a website." This echoes studies that reveal persistent confusion about how to define and evaluate online information sources. ${ }^{46}$ As a result, clear instruction about information structures, characteristics, and authorship (as described by the ACRL Framework ${ }^{47}$ ) remains essential when teaching students citation skills. We also found no consensus among faculty or students on who was perceived to be the "authority" on the application of citation standards. However, it was heartening to see that both students and faculty held the library in high esteem, with strong praise for the citation expertise of librarians. In the time since our study was conducted, the library has been increasingly involved in executive-level conversations and projects and continues to advocate for a more unified approach to academic integrity across the university. To maintain our reputation for citation expertise, the library will also continue to promote and further develop our referencing support services to all stakeholders. There were several useful participant suggestions about the guide and citation and referencing support services that the library welcomed. Table 1 below summarizes the main points made and how the library intends to respond to them.

\section{TABLE 1}

Participant Suggestions for Citation and Referencing Support Services

\begin{tabular}{|l|l|}
\hline Participant Comment & Library Response \\
\hline $\begin{array}{l}\text { Make a long-form hard copy of the guide } \\
\text { available }\end{array}$ & $\begin{array}{l}\text { Creation of a more comprehensive printable version of } \\
\text { the guide }\end{array}$ \\
\hline $\begin{array}{l}\text { Make a "question and answer" service available; } \\
\text { provide prompts when typing in the search box }\end{array}$ & $\begin{array}{l}\text { Increase promotion and visibility of the library's AskUs } \\
\text { knowledge bank }\end{array}$ \\
\hline $\begin{array}{l}\text { Make "secondary source citation" information } \\
\text { more obvious }\end{array}$ & $\begin{array}{l}\text { Provide examples on each relevant page of the guide, } \\
\text { along with a statement describing appropriate ways to } \\
\text { use the method. }\end{array}$ \\
\hline Clarify language within the guide & $\begin{array}{l}\text { Choose more explicit terms such as "secondary citation } \\
\text { (source within a source)" and "Video and Audio" }\end{array}$ \\
\hline Fix access issues with video tutorials & Add captions to all video tutorials \\
\hline $\begin{array}{l}\text { Improve the user experiences of staff support } \\
\text { at service desks }\end{array}$ & $\begin{array}{l}\text { Increase efforts to train staff to ensure positive user } \\
\text { experiences }\end{array}$ \\
\hline
\end{tabular}

\section{Conclusion}

Citation and referencing instruction and support provide an essential foundation for students who are beginning their academic journey. The library's move to become the designated authority on citation styles arose from the need to improve the user experience in this area. The study outlined in this paper was designed to give the library and wider university 
community an insight into the experience of staff and students who had engaged with the online citation guide and investigate whether the library was meeting its remit to actively and accurately support students in using the three endorsed citation styles. The findings from this study highlighted the considerable challenges experienced by faculty and students when teaching and learning citation skills. Results indicate that students motivated by fear of adverse outcomes will divert their attention to mechanical aspects while losing sight of the logical and ethical reasons for citing sources. Librarians and faculty fulfill complementary roles in providing referencing support. Positive messages about academic integrity along with clear, consistent referencing support materials are important components in nurturing confident learners. Just as referencing is an iterative process, so is ensuring that a referencing guide is effective. Future studies will involve live usability testing to better understand the needs of our users.

\section{Acknowledgments}

The authors would like to thank the University of Notre Dame Australia's library staff and the School of Education's faculty for their assistance with this project.

\section{Notes}

1. In Australian higher education institutions, librarians hold nonfaculty professional status. This paper therefore uses the term "faculty" for academic educators and "library professionals" to describe those employed in an academic library.

2. International Center for Academic Integrity, The Fundamental Values of Academic Integrity (2017), accessed November 8, 2020, https://www.academicintegrity.org/wp-content/uploads/2017/12/Fundamental-Values-2014.pdf. 16; The University of Notre Dame Australia, Policy: Academic Integrity (Students) (2020), accessed November 8, 2020, https://www.notredame.edu.au/_data/assets/pdf_file/0012/2037/POLICY-Student-Academic-Integrity.pdf. 6.

3. "Referencing" is used as a gerund in this paper; it is frequently used for citation/citing in academic parlance in Australia and the United Kingdom. Referencing and citation/citing are used in this paper interchangeably.

4. Association of College \& Research Libraries, Framework for Information Literacy for Higher Education (2015), accessed November 8, 2020, www.ala.org/acrl/sites/ala.org.acrl/files/content/issues/infolit/framework1.pdf.

5. Stephanie Margolin and Wendy Hayden, "Beyond Mechanics: Reframing the Pedagogy and Development of Information Literacy Teaching Tools," Journal of Academic Librarianship 41, no. 5 (2015); Karen Gravett and Ian M. Kinchin, "Referencing and Empowerment: Exploring Barriers to Agency in the Higher Education Student Experience," Teaching in Higher Education 25, no. 1 (2020); Karen Gravett and Ian M. Kinchin, "The Role of Academic Referencing within Students' Identity Development," Journal of Further and Higher Education (2020); Iris Vardi, "Developing Students' Referencing Skills: A Matter of Plagiarism, Punishment and Morality or of Learning to Write Critically?" Higher Education Research E Development 31, no. 6 (2012).

6. Gravett and Kinchin, "The Role of Academic Referencing within Students' Identity Development"; Gravett and Kinchin, "Referencing and Empowerment."

7. Alan Hamlin et al., "A Comparison of University Efforts to Contain Academic Dishonesty," Journal of Legal, Ethical and Regulatory Issues 16, no. 1 (2013); Erika Löfström et al., "Who Teaches Academic Integrity and How Do They Teach It?" Higher Education 69, no. 3 (2015); Saadia Mahmud and Tracey Bretag, "Postgraduate Research Students and Academic Integrity: 'It's About Good Research Training',' Journal of Higher Education Policy and Management 35, no. 4 (2013); Russell Michalak et al., "Faculty Perceptions of Plagiarism: Insight for Librarians' Information Literacy Programs," College E Research Libraries 79, no. 6 (2018); Lesley Sefcik, Michelle Striepe, and Jonathan Yorke, "Mapping the Landscape of Academic Integrity Education Programs: What Approaches Are Effective?" Assessment \& Evaluation in Higher Education 45, no. 1 (2020).

8. Tracey Bretag et al., "Academic Integrity Standards: A Preliminary Analysis of the Academic Integrity Policies at Australian Universities," Proceedings of AuQF 2011: Demonstrating Quality (Melbourne, VIC: Australian Quality Forum, 2011), https://ro.uow.edu.au/cgi/viewcontent.cgi?article=1332\&context=asdpapers.

9. Löfström et al., "Who Teaches Academic Integrity and How Do They Teach It?"

10. Martine Peters, Tessa Boies, and Sonia Morin, "Teaching Academic Integrity in Quebec Universities: Roles Professors Adopt," Frontiers in Education 4, no. 99 (2019). 
11. Michalak et al., "Faculty Perceptions of Plagiarism."

12. Iris Vardi, Effective Feedback for Student Learning in Higher Education (Milperra, NSW: Higher Education Research and Development Society of Australasia, 2012).

13. Cary A. Brown et al., "Promoting Academic Writing/Referencing Skills: Outcome of an Undergraduate E-Learning Pilot Project," British Journal of Educational Technology 39, no. 1 (2008); Bruce Macfarlane, Jingjing Zhang, and Annie Pun, "Academic Integrity: A Review of the Literature," Studies In Higher Education 39, no. 2 (2012); Sarah Park, Lori A. Mardis, and Connie Jo Ury, "I've Lost My Identity-Oh, There It Is. In a Style Manual: Teaching Citation Styles and Academic Honesty," Reference Services Review 39, no. 1 (2011); Kerry Shephard et al., "Teaching Research Integrity in Higher Education: Policy and Strategy," Journal of Higher Education Policy and Management 37, no. 6 (2015).

14. Melanie Greenwood et al., "Postgraduate Nursing Student Knowledge, Attitudes, Skills, and Confidence in Appropriately Referencing Academic Work," Journal of Nursing Education 53, no. 8 (2014).

15. Tracey Bretag et al., "'Teach Us How to Do It Properly!': An Australian Academic Integrity Student Survey," Studies in Higher Education 39, no. 7 (2014).

16. Martine Peters and Alain Cadieux, "Are Canadian Professors Teaching the Skills and Knowledge Students Need to Prevent Plagiarism?" International Journal for Educational Integrity 15, no. 1 (2019).

17. Gravett and Kinchin, "Referencing and Empowerment."

18. Gravett and Kinchin, "The Role of Academic Referencing within Students' Identity Development."

19. Alison J. Head and Michael B. Eisenberg, "Assigning Inquiry: How Handouts for Research Assignments Guide Today's College Students. Project Information Literacy Progress Report," Project Information Literacy (2010), https://files.eric.ed.gov/fulltext/ED535162.pdf.

20. Association of College \& Research Libraries, Standards for Libraries in Higher Education (2018), www.ala. org/acrl/standards/standardslibraries; Michalak et al., "Faculty Perceptions of Plagiarism."

21. Boglarka S. Huddleston et al., "Faculty Perspectives on Undergraduate Research Skills: Nine Core Skills for Research Success," Reference and User Services Quarterly 59, no. 2 (2019); Peters, Boies, and Morin, "Teaching Academic Integrity in Quebec Universities."

22. Stephanie Evers Ard and Franklin Ard, "Faculty Expectations of a University Library and Writing Center in Preventing Plagiarism," Southeastern Librarian 66, no. 2 (2018).

23. Brown et al., "Promoting Academic Writing/Referencing Skills"; Kathleen Gray et al., "Web 2.0 Authorship: Issues of Referencing and Citation for Academic Integrity," Internet and Higher Education 11, no. 2 (2008); Katie Greer and Shawn McCann, "Everything Online Is a Website: Information Format Confusion in Student Citation Behaviors," Communications in Information Literacy 12, no. 2 (2018).

24. John A. Kargbo, “Undergraduate Students' Problems with Citing References," Reference Librarian 51, no. 3 (2010).

25. Kargbo, "Undergraduate Students' Problems with Citing References"; Park, Mardis, and Ury, "I've Lost My Identity."

26. Park, Mardis, and Ury, "I've Lost My Identity."

27. Lise Buranen, "A Safe Place: The Role of Librarians and Writing Centers in Addressing Citation Practices and Plagiarism," Knowledge Quest 37, no. 3 (2009).

28. Stephanie Evers Ard and Franklin Ard, "The Library and the Writing Center Build a Workshop: Exploring the Impact of an Asynchronous Online Academic Integrity Course," New Review of Academic Librarianship (2019); Stephanie Bell, "Addressing Student Plagiarism from the Library Learning Commons," Information and Learning Science 119, no. 3/4 (2018); Katie Greer et al., "Beyond the Web Tutorial: Development and Implementation of an Online, Self-Directed Academic Integrity Course at Oakland University," Journal of Academic Librarianship 38, no. 5 (2012).

29. Ard and Ard, "The Library and the Writing Center Build a Workshop"; Bell, "Addressing Student Plagiarism from the Library Learning Commons"; Carole Gibbs et al., "Mapping the Roadmap: Using Action Research to Develop an Online Referencing Tool," Journal of Academic Librarianship 41, no. 4 (2015); Greer et al., "Beyond the Web Tutorial"; Park, Mardis, and Ury, "I've Lost My Identity"; Christy R. Stevens, "Citation Generators, OWL, and the Persistence of Error-Ridden References: An Assessment for Learning Approach to Citation Errors," Journal of Academic Librarianship 42, no. 6 (2016).

30. John Cox, "Positioning the Academic Library within the Institution: A Literature Review," New Review of Academic Librarianship 24, no. 3/4 (2018); Bruce Massis, "The User Experience (UX) in Libraries," Information and Learning Science 119, no. 3/4 (2018).

31. Andy Priestner and Matt Borg, User Experience in Libraries: Applying Ethnography and Human-Centred Design (Farnham, Surrey, UK: Ashgate, 2016), https://doi.org/10.4324/9781315548609.

32. Voice Record Pro, iPad ed. (Dayana Networks, 2013).

33. NVivo 11, Pro ed. (QSR International, 2015).

34. Virginia Braun and Victoria Clarke, "Using Thematic Analysis in Psychology," Qualitative Research in Psychology 3, no. 2 (2006). 
35. Nancy Van Note Chism and Shrinika Weerakoon, "APA, Meet Google: Graduate Students' Approaches to Learning Citation Style," Journal of the Scholarship of Teaching and Learning 12, no. 2 (2012).

36. Steve Krug, Don't Make Me Think! A Common Sense Approach to Web Usability, 3rd ed. (Berkeley, CA: New Riders, 2014); Priestner and Borg, User Experience in Libraries.

37. Löfström et al., “Who Teaches Academic Integrity and How Do They Teach It?"; Shephard et al., “Teaching Research Integrity in Higher Education."

38. Macfarlane, Zhang, and Pun, "Academic Integrity"; Vardi, "Developing Students' Referencing Skills."

39. Gravett and Kinchin, "Referencing and Empowerment."

40. Sefcik, Striepe, and Yorke, "Mapping the Landscape of Academic Integrity Education Programs," 41.

41. Alison J. Head, "Learning the Ropes: How Freshmen Conduct Course Research Once They Enter College,"

Project Information Literacy (2013), https://files.eric.ed.gov/fulltext/ED548262.pdf.

42. Vardi, "Developing Students' Referencing Skills."

43. Margolin and Hayden, "Beyond Mechanics."

44. Cox, "Positioning the Academic Library within the Institution," 223.

45. Bretag et al., "Academic Integrity Standards"; Löfström et al., "Who Teaches Academic Integrity and How Do They Teach It?"; Michalak et al., "Faculty Perceptions of Plagiarism"; Peters and Cadieux, "Are Canadian Professors Teaching the Skills and Knowledge Students Need to Prevent Plagiarism?"; Sefcik, Striepe, and Yorke, "Mapping the Landscape of Academic Integrity Education Programs."

46. Brown et al., "Promoting Academic Writing/Referencing Skills"; Gibbs et al., "Mapping the Roadmap"; Gray et al., "Web 2.0 Authorship"; Greer and McCann, "Everything Online Is a Website."

47. Association of College \& Research Libraries, Framework for Information Literacy for Higher Education. 